\title{
Sustained-Release Fampridine (4-Aminopyridine) in Multiple Sclerosis: Efficacy and Impact on Motor Function
}

\author{
Meheroz H. Rabadi · Kimberly Kreymborg • \\ Andrea S. Vincent
}

Published online: 20 July 2013

(c) The Author(s) 2013. This article is published with open access at Springerlink.com

\begin{abstract}
Objective The aim of this study was to determine the efficacy of sustained-release fampridine (4-aminopyridine) in veterans with multiple sclerosis (MS) with limited ambulatory ability, and its impact on motor function in an outpatient setting.

Design Retrospective.

Setting Tertiary referral center [Veterans Affairs (VA) Medical Center].

Participants Veterans; 20 MS patients were prescribed dalfampridine (10 mg twice daily) due to their difficulty with walking based on patient and caregiver report and clinician impression of change in the ability to ambulate based on prior 10 -meter $(10 \mathrm{M})$ and 2 -minute walk tests (2MWTs).

Intervention Not applicable.

Main Outcome Measures The primary outcome measures were mean changes in walking speed (10M walk test), walking distance (2MWT), and Total Functional
\end{abstract}

Electronic supplementary material The online version of this article (doi:10.1007/s40268-013-0020-x) contains supplementary material, which is available to authorized users.

M. H. Rabadi ( $\square)$

Department of Neurology, Oklahoma University and Oklahoma City VA Medical Center, 921 NE 13th Street, Oklahoma City, OK 73034, USA

e-mail: rabadimh@gmail.com

M. H. Rabadi · K. Kreymborg

Oklahoma City VA Medical Center, Oklahoma City, OK, USA

A. S. Vincent

Cognitive Science Research Center, University of Oklahoma

at Norman (Statistician), Oklahoma City, OK, USA
Independence Measure (TFIM). Improvement of $>20 \%$ in walking speed was indicated as a clinically meaningful change.

Results Treatment with dalfampridine resulted in significant improvement in walking speed and endurance $(p<0.05)$. Walking speed increased by $33 \%$ and walking endurance by $31 \%$, representing clinically meaningful improvement. This change was not influenced by change in muscle tone. This improvement in mobility was associated with a clinically significant change in motor function. Adverse effects, including insomnia, dizziness, and headache, were experienced by five patients who discontinued the medication after a minimum of 4 weeks.

Conclusion Treatment with dalfampridine resulted in clinically relevant improvements in walking speed and endurance in MS patients with limited ambulation and helped improve their motor function.

\section{Introduction}

Gait disturbance is reported by many patients with multiple sclerosis (MS) as a major primary symptom [1] and occurs in $50 \%$ of cases [2]. It presents early in the course of the disease [3] and is perceived as a major health issue by patients with MS [4]. It is a limiting factor with progression of the disease [1]. This gait disturbance is caused by muscle weakness and spasticity from pyramidal tract lesions, ataxia from cerebellar lesions, sensory disturbance due to dorsal column lesions, and vestibular and visual dysfunction, or a combination of these symptoms [5]. It impacts upon their activities of daily living and emotional state, and thus decreases their quality of life and health state [6]. Recommended treatment options specific to gait disturbance have mainly been physical therapy measures 
such as exercises for strengthening affected muscles, reducing spasticity, use of ankle-foot braces, and rolling walkers. None of the current immunomodulatory therapies have any effect on improving gait disturbance. Thus, gait disturbance is an important outcome measure in the treatment and rehabilitation of patients with MS.

Fampridine (4-aminopyridine) is a voltage-dependent potassium channel-blocker [7,8] found to restore action potential conduction in poorly myelinated central nerve fibers [9] and also affects synaptic transmission and neuronal excitability [10]. Several clinical trials have shown fampridine use has been associated with clinical improvement in MS patients [11-14]. The adverse effects of fampridine are confusion, seizure disorder, and balance disorders $[15,16]$. These adverse effects are directly related to its dosing and plasma concentration [17, 18]. Recently, two phase III studies showed sustained-release oral fampridine (dalfampridine), a long-acting form with similar physiological action, improved walking ability in $35-43 \%$ of MS patients with ambulatory difficulty compared with $8-9 \%$ for placebo. In the treated group, the improvement in walking speed was $25 \%$ during the treatment period $[19,20]$. Dalfampridine is nowadays considered the standard of care for MS patients with ambulatory difficulty.

The objective of the present study was to replicate these findings in veterans with MS in an outpatient setting (realworld environment) and its impacts on their motor function.

\section{Methods}

\subsection{Study Population and Procedures}

This study was approved by the Institutional Review Board of the University of Oklahoma and the Veterans Affairs Medical Center Research and Development Committee. Retrospective chart review was conducted for MS patients $(n=20)$ regularly followed in an outpatient MS clinic who were prescribed dalfampridine (10 $\mathrm{mg}$ twice daily). The inclusion criteria were difficulty with walking based on (i) the patient and caregiver report; and (ii) clinician's impression of change in ambulation based on prior 10 -meter (10M) and 2-minute walk tests (2MWT). Exclusion criteria included (i) renal impairment (creatinine clearance $<50 \mathrm{~mL} / \mathrm{min}$ ); (ii) prior or current history of seizure disorder; and (iii) presence of disease instability as evidenced by recent MS relapse and/or change in immunomodulatory therapy. Patients were non-Hispanic White $(85 \%)$ males $(100 \%)$, aged $33-72$ years $(55.3 \pm 10.8$; mean $\pm \mathrm{SD}$ ) (see Table 1).

Data collected from the charts of the 20 patients included demographic information, MS characterization, and
Table 1 Demographic variables of 20 MS patients on dalfampridine [mean $\pm \mathrm{SD}$ (range) or $n(\%)$ where applicable]

\begin{tabular}{|c|c|}
\hline Grouping variables & Sample \\
\hline Age (years) & $55.3 \pm 10.8$ \\
\hline Sex (M:F) & 20:0 \\
\hline Ethnicity (White/Black) & $17: 3$ \\
\hline Age of MS onset (years) & $35.2 \pm 11.9(20-58)$ \\
\hline MS duration (years) & $23.5 \pm 14.5(5-47)$ \\
\hline \multicolumn{2}{|l|}{ MS types $[n(\%)]$} \\
\hline Relapsing-remitting & $11(55)$ \\
\hline Secondary-progressive & $6(30)$ \\
\hline Primary-progressive & $3(15)$ \\
\hline \multicolumn{2}{|l|}{ On initial evaluation } \\
\hline MMSE & $28.0 \pm 3.2$ \\
\hline Visual $(n=17)$ & $3(18)$ \\
\hline Upper limb muscle strength $(n=19)$ & $4.2 \pm 0.9$ \\
\hline Lower limb muscle strength $(n=19)$ & $3.9 \pm 0.9$ \\
\hline Sensory complaints [yes] $(n=17)$ & $9(53)$ \\
\hline Cerebellar complaints [yes] $(n=17)$ & $10(59)$ \\
\hline \multicolumn{2}{|l|}{ Gait } \\
\hline Normal & $4(20)$ \\
\hline Ataxic & $3(15)$ \\
\hline Spastic & $9(45)$ \\
\hline Unable & $1(5)$ \\
\hline Unknown & $3(15)$ \\
\hline LEMMT & $3.9 \pm 0.9(2-5)$ \\
\hline 10 -meter walk test $(\mathrm{sec})$, initial $(n=19)$ & $28.4 \pm 18.7$ \\
\hline 2-minute walk test $(\mathrm{ft})$, initial $(n=13)$ & $155.4 \pm 94.5$ \\
\hline Modified Ashworth Score, initial $(n=15)$ & $0.5 \pm 0.7(0-2)$ \\
\hline EDSS score, initial $(n=19)$ & $5.5 \pm 1.9(1.5-7.5)$ \\
\hline TFIM score, initial $(n=17)$ & $83.7 \pm 13.3(57-104)$ \\
\hline Immunomodulators $[n(\%)]^{\mathrm{a}}$ & $13(65)$ \\
\hline Avonex & $4(20)$ \\
\hline Copaxone & $8(40)$ \\
\hline Natalizumab & $1(5)$ \\
\hline
\end{tabular}

EDSS Expanded Disability Status Scale, $F$ female, LEMMT Lower Extremity Manual Muscle Test, $M$ male, MMSE Mini-Mental State Examination, $M S$ multiple sclerosis, TFIM Total Functional Independence Measure

${ }^{\text {a }}$ Concurrent treatment with interferon, glatiramer, natalizumab

initial and follow-up scores for the following: Medical Research Council (MRC) lower extremity muscle strength (LEMMT), Total Functional Independence Measure (TFIM), Modified Ashworth Scale (MAS), 10M walk time, and 2MWT distance. Consistent with Veterans Affairs (VA) guidelines for veterans on dalfampridine, response to treatment, compliance, adverse effects, and withdrawals were assessed at 4, 3, 6, and 12 months following treatment initiation. All data were prospectively recorded in the computerized patient record system as part of patient care by a clinician who was unaware of the study hypothesis. 


\subsection{Primary Outcome Measures}

The 10M and 2MWT were administered to the MS patients to assess general walking speed and capacity [21, 22]. The $10 \mathrm{M}$ walk test measures walking speed (in seconds) of the patient over a set distance. The patient was instructed to walk at usual speed using whatever aid was needed as in everyday life. This test was selected as it is simple and quick to administer, inexpensive, and is easily generalizable to community walking [21]. It has been found to be a reliable, valid, and sensitive measure [23-25]. The limitation of the $10 \mathrm{M}$ walk test is that the quality of gait is not assessed and a ceiling effect is apparent at normal walking speed $(1.2-1.4 \mathrm{~m} / \mathrm{s})$ [26].

The 2MWT, commonly used to measure walking capacity or endurance in persons with cardiac and pulmonary disease, assessed endurance in these patients. The patient was instructed to cover as much ground as possible in 2 min walking at a comfortable speed using ambulation aids as used in their everyday life. Rest periods were allowed during the evaluation. The distance (in feet) covered was measured using a Trumeter Mini-Measure Distance-Measuring Wheel, a device that accurately measures up to 10,000 feet. The 2-minute timed walk test is a valid, reliable, and sensitive measure that is easy to administer $[22,27]$. The limiting factors for the 2-minute timed walk test are pain, mood, and cardiovascular fitness, which can influence the result [28].

The MAS was administered to measure spasticity [29]. It is widely used, easy to administer, and has good validity but limited reliability [30-32]. Research has shown that disability tends to be more related to weakness than spasticity [33]. Therefore, the association between ambulatory gains and spasticity changes were examined.

MRC scale graded the lower extremity muscle strength (LEMMT). It is a widely used ordinal measure of power, with $0=$ no movement to $5=$ normal movement. It has established validity and reliability [34]. The major limitation of MRC grading is that the scale neither considers the range of motion (ROM) for which a movement can be performed nor defines the strength of resistance against which a movement can be performed [35].

The TFIM assessed MS-related disability. The TFIM is a reliable [36] and valid [37] functional assessment instrument that is widely used in many rehabilitation settings [38] to measure the degree of disability [39]. The TFIM has 18 items; each item is scored on an ordinal scale ranging from 1 ('total assist': patient performs $<25 \%$ of task) to 7 ('complete independence'). The resulting score indicates the level of assistance needed to achieve independence and ranges from 18 (totally dependent) to 126 (independent). Thus, increased disability is reflected in lower TFIM scores.

\subsection{Statistical Analysis}

All data analyses for this paper were generated using SAS software, Version 9.2 of the SAS System for Windows (SAS Institute Inc., Cary, NC, USA). The significance level for all statistical tests was set a priori at $p<0.05$. Paired $t$ tests were used to compare the pre-treatment and 12-month follow-up assessments of spasticity, walking speed, walking capacity, and TFIM. Improvement of $>20 \%$ in walking speed was used to detect clinically meaningful change. Pearson correlation coefficients were examined to describe the relationship between $10 \mathrm{M}$ and 2MWT at initial evaluation and 12-month follow-up, as well as between changes in spasticity and ambulation. A 'responder status' was defined based on faster walking speed for three of the four visits during the treatment period [19]. The difference in the proportion of responders between the continuation and discontinuation group was analyzed using the Chi-square test.

Secondary analyses were conducted comparing initial and 12-month follow-up scores on the 10M, 2MWT, and MAS according to MS type (relapsing-remitting, RR; secondary-progressive, SP; or primary-progressive, PP), MS severity (mild: Expanded Disability Status Scale [EDSS] score $\leq 4.0$, or moderate-to-severe: EDSS $\geq 4.5$ ), and duration of dalfampridine use (discontinued after a minimum of 4 weeks or continued 12-months use) using repeated measures of analysis of variance (MS type) and paired $t$ tests. These analyses were not included in the primary analyses because of the low sample sizes after dividing the sample into groups.

\section{Results}

The mean age of MS onset was 35.2 years (SD 11.9) and mean duration of MS condition was 23.5 years (SD 14.5). The most common type of MS was RR $(55 \%)$ followed by SP (30 \%) and PP (15\%) types. The initial mean MAS, 10M, 2MWT, and LEMMT test scores across the entire sample were $0.5 \pm 0.7,28.4 \pm 18.7 \mathrm{~s}, 155.4 \pm 94.5$ feet, and $3.9 \pm 0.9(2-5)$, respectively. The mean initial EDSS and TFIM scale scores were $5.5 \pm 1.9$, and $83.7 \pm 13.3$, respectively. Thus, patients with MS were moderately functionally impaired with little muscle tone (spasticity).

Table 2 presents the change in the 10M and 2MWT, and MAS, LEMMT, and TFIM scores. Data were missing for several patients; therefore, values are only presented for those with data at both timepoints. Significant improvement was observed for walking speed $(p=0.008)$, and walking distance $(p=0.03)$, but not for spasticity $(p=0.10)$ and lower extremity muscle strength $(p=1.0)$. The change in $10 \mathrm{M}$ represented a $33 \%$ improvement in 
Table 2 Initial and follow-up 10-meter, 2-minute timed walk test and Modified Ashworth Scale (mean \pm SD) on initial evaluation and at 12-month follow-up

\begin{tabular}{lccccc}
\hline Variable & Initial & 12-months follow-up & $\Delta$ & $\%$ Change & $p$-value \\
\hline 10-meter walk test $(n=13)$ & $32.1(18.9)$ & $21.5(11.3)$ & $-10.5(11.9)$ & -32.7 & $\mathbf{0 . 0 0 8}$ \\
2-minute walk test $(n=8)$ & $163.8(97.1)$ & $215.0(88.8)$ & $51.3(51.4)$ & 31.3 & $\mathbf{0 . 0 3}$ \\
Modified Ashworth Scale $(n=10)$ & $0.4(0.8)$ & $0.8(0.9)$ & $0.4(0.7)$ & 100 & 0.10 \\
LEMMT $(n=17)$ & $3.9(0.9)$ & $3.9(1.1)$ & $0(1.1)$ & 0 & 1.0 \\
TFIM score $(n=14)$ & $84.7(13.2)$ & $102.2(13.6)$ & $17.5(19.3)$ & 20.7 & 0.07 \\
\hline
\end{tabular}

LEMMT Lower Extremity Manual Muscle Test, TFIM Total Functional Independence Measure

Bold value indicates statistical significant differences

walking speed, exceeding the minimally important clinical difference of $20 \%$, and endurance improved by $31 \%$. While the MAS score doubled, the score still fell in the range representing no change in muscle tone. Likewise, there was no change in the LEMMT score. The correlations between MAS change and change in walking speed and endurance did not achieve significance $(p>0.05)$. This improvement in ambulatory ability was mirrored by an improvement in motor function ( $p=0.07$ ); however, it did not achieve statistical significance.

The correlation between walking speed (10M) and walking distance (2MWT) was examined for scores obtained on initial evaluation and at 12-month follow-up (Fig. 1). The correlation at baseline was not significant $r=-0.38, p=0.22(n=12)$. However, at 12-months, there was a significant inverse relationship between walking speed and walking distance, $r=-0.88, p<0.0001$ $(n=13)$, indicating that the faster walkers were also able to walk further distances.

The number of patients who met the responder criterion was $6 / 12(50 \%)$ in the continuation group compared with $2 / 8(25 \%)$ in the discontinuation group $(p=0.37)$. There was no difference in change in leg strength at 12 months between responders and non-responders $(-0.2 \pm 1.0$ vs. $0.1 \pm 1.1$; mean $\pm \mathrm{SD} ; p=0.63$ ).

\subsection{Secondary Analyses}

No significant differences were observed in change at 12 months for $10 \mathrm{M}, 2 \mathrm{MWT}$, or MAS according to MS type (see Appendix 1, electronic supplementary material [ESM]) or MS severity (see Appendix 2, ESM) [all $p>0.05]$. However, SP and PP MS patients had the fastest walking speed and had more endurance compared with the RR MS patients when on dalfampridine. Similarly, moderate to severely disabled MS patients had the fastest walking speed and had more endurance compared with the mildly disabled MS patients when on dalfampridine. Although no significant differences were observed in change at 12 months for 10M, 2MWT, and MAS scores according to the duration for which dalfampridine was taken $(p>0.5)$ (see Appendix 3, ESM), it did show that veterans who took dalfampridine for a minimum of 4 weeks were able to maintain faster walking speed and endurance at 12 months when compared with those who continued taking their medication for 12 months.

\section{Discussion}

Results of this study in MS patients who were on stable immunomodulatory therapy confirm the beneficial effect of dalfampridine in the treatment of veterans with MS and ambulatory dysfunction [16, 19], but also expands upon the findings of Goodman et al. [19, 20] by demonstrating the following: (i) improved ambulation persists when dalfampridine is taken over an extended time period (12 months); (ii) the change in ambulation speed and endurance is both clinically relevant and significant; (iii) the changes in ambulation were not influenced by change in muscle tone (spasticity), or improvement in muscle strength in the legs; and (iv) this improvement in ambulation was associated with an improvement in motor function.

In terms of the major outcome measures of walking speed and endurance, walking speed improved by $33 \%$ with a simultaneous increase in endurance (the distance ambulated) by $31 \%$ for the whole group. Studies by Goodman et al. [19, 20] showed the average change from baseline in walking speed in the fampridine-treated group was $25 \%$, which is similar to our study results, and this change was maintained during the 12-month treatment period. This improvement in walking speed translated into improved endurance, resulting in them becoming community ambulators [40, 41]. The improvements in walking speed exceed $\geq 20 \%$, which is considered to represent clinically relevant change [42-44].

While the small sample sizes limit the power and generalizability of the analyses, the current study also demonstrated that, of the MS types, PP and SP made the most gains in ambulation compared with the RR group. This was not unusual given that the PP and SP groups were slow in ambulation to begin with and ambulated shorter distances 
Fig. 1 Relationship between the 10-meter and 2-minute walk tests
Relationship of Initial and 12-month Follow-up 10-meter and 2-min Walk Tests

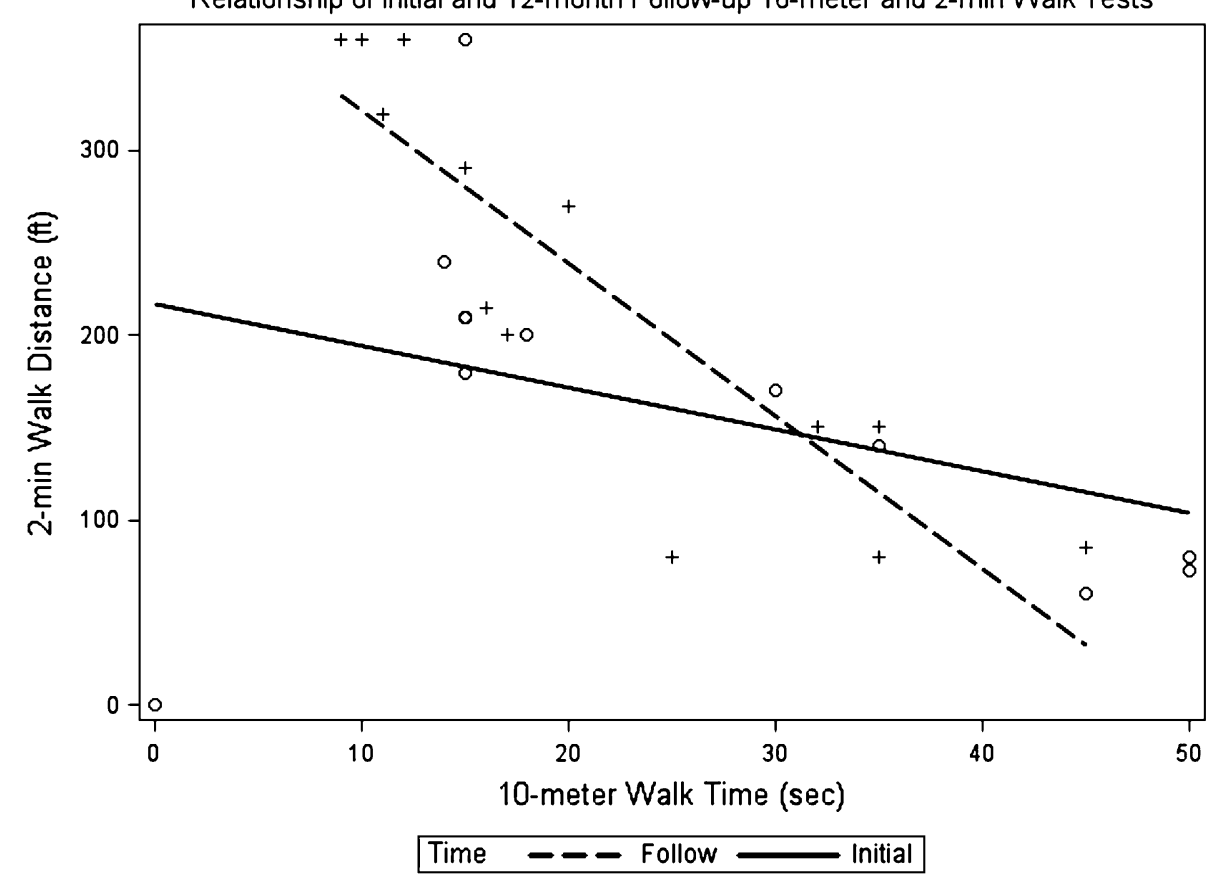

(more impaired). Similar changes were observed for the more impaired patients (moderate to severe impairment) when compared with mildly impaired patients. Both sets of patients who continued taking the medication and those who discontinued after a minimum of 4 weeks use were able to maintain their improved walking speed and endurance at 12-month follow-up. This improvement in ambulatory ability translated into improved motor function. The change in TFIM score was 18 points. A TFIM change of $\sim 20$ points is considered a minimally clinically significant change [45]. This implied that patients who were now able to ambulate more were now more able to selfcare and thus less dependent on their caregivers.

The present study also revealed a negative correlation between walking speed and endurance on initial evaluation and 12-month follow-up, with slower walking patients also ambulating shorter distances. However, this association was statistically significant at 12-month follow-up only. This finding suggests that the results of the two ambulation tests are better aligned at the follow-up assessment.

Eight patients $(40 \%)$ discontinued dalfampridine use after 4 weeks. Three patients did so volitionally due to perceived lack of benefit, while in five patients this was due to adverse effects which included insomnia in two patients, and weakness, dizziness, and headache in one patient each.

The limitations of this study include (i) the small sample size; (ii) the sample comprised of veterans who were all White men; (iii) it was a single institution study; and (iv) retrospective analysis with missing data may bias the findings of this study. However, the strength of this study lies in the longitudinal follow-up for 12 months with $100 \%$ adherence to intake in $60 \%(12 / 20)$ of the patient population studied.

\section{Conclusion}

Ambulation is crucial for patients with MS. This study provides evidence that treatment with dalfampridine in veterans with MS with ambulatory dysfunction produces clinically meaningful improvement in walking speed and endurance in the absence of meaningful change in muscle tone. This improvement in ambulation was associated with improved motor functioning.

Author contributions Study concept and design was undertaken by Meheroz H. Rabadi; acquisition of data was carried out by Kimberly Kreymborg and Meheroz $\mathrm{H}$. Rabadi; analysis and interpretation of data was conducted by Meheroz H. Rabadi and Andrea S. Vincent; drafting of the manuscript was undertaken by Meheroz H. Rabadi, Kimberly Kreymborg and Andrea S. Vincent; critical revision of the manuscript for important intellectual content was undertaken by Meheroz H. Rabadi and Andrea S. Vincent; statistical analysis was conducted by Andrea S. Vincent; and study supervision was carried out by Meheroz H. Rabadi.

Conflicts of interest Meheroz H. Rabadi, Kimberly Kreymborg and Andrea S. Vincent declare no conflicts of interest.

Open Access This article is distributed under the terms of the Creative Commons Attribution Noncommercial License which permits any noncommercial use, distribution, and reproduction in any medium, provided the original author(s) and the source are credited. 


\section{References}

1. Panitch H, Applebee A. Treatment of walking impairment in multiple sclerosis: an unmet need for a disease-specific disability. Expert Opin Pharmacother. 2011;12(10):1511-21.

2. Paltamaa J, Sarasoja T, Leskinen E, Wikström J, Mälkiä E. Measures of physical functioning predict self-reported performance in self-care, mobility, and domestic life in ambulatory persons with multiple sclerosis. Arch Phys Med Rehabil. 2007;88(12):1649-57.

3. Martin CL, Phillips BA, Kilpatrick TJ, Butzkueven H, Tubridy N, McDonald E, Galea MP. Gait and balance impairment in early multiple sclerosis in the absence of clinical disability. Mult Scler. 2006;12(5):620-8.

4. Heesen C, Böhm J, Reich C, Kasper J, Goebel M, Gold SM. Patient perception of bodily functions in multiple sclerosis: gait and visual function are the most valuable. Mult Scler. 2008;14(7):988-91. doi:10.1177/1352458508088916.

5. Rodgers MM, Mulcare JA, King DL, Mathews T, Gupta SC, Glaser RM. Gait characteristics of individuals with multiple sclerosis before and after a 6-month aerobic training program. J Rehabil Res Dev. 1999;36(3):183-8.

6. Zwibel HL. Contribution of impaired mobility and general symptoms to the burden of multiple sclerosis. Adv Ther. 2009;26(12):1043-57. doi:10.1007/s12325-009-0082-x.

7. Chwieduk CM, Keating GM. Dalfampridine extended release: in multiple sclerosis. CNS Drugs. 2010;24(10):883-91.

8. Judge SI, Bever CT Jr. Potassium channel blockers in multiple sclerosis: neuronal $\mathrm{Kv}$ channels and effects of symptomatic treatment. Pharmacol Ther. 2006;111(1):224-59.

9. Kaji R, Sumner AJ. Effects of 4-aminopyridine in experimental CNS demyelination. Neurology. 1988;38(12):1884-7.

10. Mainero C, Inghilleri M, Pantano P, Conte A, Lenzi D, Frasca V, Bozzao L, Pozzilli C. Enhanced brain motor activity in patients with MS after a single dose of 3,4-diaminopyridine. Neurology. 2004;62(11):2044-50.

11. Jones RE, Heron JR, Foster DH, Snelgar RS, Mason RJ. Effects of 4-aminopyridine in patients with multiple sclerosis. J Neurol Sci. 1983;60(3):353-62.

12. Stefoski D, Davis FA, Faut M, Schauf CL. 4-Aminopyridine improves clinical signs in multiple sclerosis. Ann Neurol. 1987; 21(1):71-7.

13. Bever CT Jr, Young D, Anderson PA, Krumholz A, Conway K, Leslie J, Eddington N, Plaisance KI, Panitch HS, Dhib-Jalbut S, et al. The effects of 4-aminopyridine in multiple sclerosis patients: results of a randomized, placebo-controlled, doubleblind, concentration-controlled, crossover trial. Neurology. 1994; 44(6):1054-9.

14. Goodman AD, Cohen JA, Cross A, Vollmer T, Rizzo M, Cohen R, Marinucci L, Blight AR. Fampridine-SR in multiple sclerosis: a randomized, double-blind, placebo-controlled, dose-ranging study. Mult Scler. 2007;13(3):357-68.

15. Lundh H, Nilsson O, Rosén I. Effects of 4-aminopyridine in myasthenia gravis. J Neurol Neurosurg Psychiatry. 1979;42(2): $171-5$.

16. Spyker DA, Lynch C, Shabanowitz J, Sinn JA. Poisoning with 4-aminopyridine: report of three cases. Clin Toxicol. 1980;16(4): 487-97.

17. Goodman AD, Brown TR, Cohen JA, Krupp LB, Schapiro R, Schwid SR, Cohen R, Marinucci LN, Blight AR, Fampridine MSF202 Study Group. Dose comparison trial of sustained-release fampridine in multiple sclerosis. Neurology. 2008;71(15): 1134-41.

18. van Diemen HA, Polman CH, van Dongen TM, van Loenen AC, Nauta JJ, Taphoorn MJ, van Walbeek HK, Koetsier JC. The effect of 4-aminopyridine on clinical signs in multiple sclerosis: a randomized, placebo-controlled, double-blind, cross-over study. Ann Neurol. 1992;32(2):123-30.

19. Goodman AD, Brown TR, Krupp LB, Schapiro RT, Schwid SR, Cohen R, Marinucci LN, Blight AR, Fampridine MS-F203 Investigators. Sustained-release oral fampridine in multiple sclerosis: a randomised, double-blind, controlled trial. Lancet. 2009;373(9665):732-8.

20. Goodman AD, Brown TR, Edwards KR, Krupp LB, Schapiro RT, Cohen R, Marinucci LN, Blight AR; MSF204 Investigators. A phase 3 trial of extended release oral dalfampridine in multiple sclerosis. Ann Neurol. 2010;68(4):494-502. doi:10.1002/ana. 22240.

21. Kempen JC, de Groot V, Knol DL, Polman CH, Lankhorst GJ, Beckerman H. Community walking can be assessed using a 10-metre timed walk test. Mult Scler. 2011;17(8):980-90.

22. Gijbels D, Dalgas U, Romberg A, de Groot V, Bethoux F, Vaney C, Gebara B, Medina CS, Maamâgi H, Rasova K, de Noordhout BM, Knuts K, Feys P. Which walking capacity tests to use in multiple sclerosis? A multicentre study providing the basis for a core set. Mult Scler. 2012;18(3):364-71.

23. Wade DT, Wood VA, Heller A, Maggs J, Langton Hewer R. Walking after stroke. Measurement and recovery over the first 3 months. Scand J Rehabil Med. 1987;19(1):25-30.

24. Bohannon RW, Andrew AW. Correlation of knee extensor muscle torque and spasticity with gait speed in patients with stroke. Arch Phys Med Rehabil. 1990;71:330-3.

25. Collen FM, Wade DT, Bradshaw CM. Mobility after stroke: reliability of measures of impairment and disability. Int Disabil Stud. 1990;12(1):6-9.

26. Bohannon RW, Andrews AW, Thomas MW. Walking speed: reference values and correlates for older adults. J Orthop Sports Phys Ther. 1996;24(2):86-90.

27. Rabadi $\mathrm{MH}$, Blau A. Admission ambulation velocity predicts length of stay and discharge disposition following stroke in an acute rehabilitation hospital. Neurorehabil Neural Repair. 2005; 19:20-6.

28. Lord SR, Menz HB. Physiologic, psychologic, and health predictors of 6-minute walk performance in older people. Arch Phys Med Rehabil. 2002;83(7):907-11.

29. Bohannon RW, Smith MB. Inter rater reliability of a modified Ashworth scale of muscle spasticity. Phys Ther. 1987;67(2): 206-7.

30. Haas BM, Bergström E, Jamous A, Bennie A. The inter rater reliability of the original and of the modified Ashworth scale for the assessment of spasticity in patients with spinal cord injury. Spinal Cord. 1996;34(9):560-4.

31. Pandyan AD, Price CI, Barnes MP, Johnson GR. A biomechanical investigation into the validity of the modified Ashworth Scale as a measure of elbow spasticity. Clin Rehabil. 2003;17(3): 290-3.

32. Blackburn M, van Vliet P, Mockett SP. Reliability of measurements obtained with the modified Ashworth scale in the lower extremities of people with stroke. Phys Ther. 2002;82(1):25-34.

33. Bohannon RW, Andrews AW. Correlation of knee extensor muscle torque and spasticity with gait speed in patients with stroke. Arch Phys Med Rehabil. 1990;71(5):330-3.

34. Paternostro-Sluga T, Grim-Stieger M, Posch M, Schuhfried O, Vacariu G, Mittermaier C, Bittner C, Fialka-Moser V. Reliability and validity of the Medical Research Council (MRC) scale and a modified scale for testing muscle strength in patients with radial palsy. J Rehabil Med. 2008;40(8):665-71. doi:10.2340/165 01977-0235.

35. Bohannon RW. Manual muscle testing of the limbs: considerations, limitations, and alternatives. Phys Ther Pract. 1992;2: $11-21$. 
36. Stineman MG, Shea JA, Jette A, et al. The Functional Independence Measure: tests of scaling assumptions, structure, and reliability across 20 diverse impairment categories. Arch Phys Med Rehabil. 1996;77:1101-8. doi:10.1016/S0003-9993(96)90130-6.

37. Stineman MG, Maislin G. Validity of functional independence measure scores. Scand J Rehabil Med. 2000;32(3):143-4. doi:10. 1080/003655000750045505.

38. Dodds TA, Martin DP, Stolov WC, Deyo RA. A validation of the functional independence measurement and its performance among rehabilitation inpatients. Arch Phys Med Rehabil. 1993;74:531-6. doi:10.1016/0003-9993(93)90119-U.

39. Granger CV. The emerging science of functional assessment: our tool for outcomes analysis. Arch Phys Med Rehabil. 1998;79: 235-40. doi:10.1016/S003-9993(98)9000-4.

40. Créange A, Serre I, Levasseur M, Audry D, Nineb A, Boërio D, Moreau T, Maison P, Réseau SINDEFI-SEP. Walking capacities in multiple sclerosis measured by global positioning system odometer. Mult Scler. 2007;13(2):220-3.
41. Fahey MC, Corben LA, Collins V, Churchyard AJ, Delatycki MB. The 25-foot walk velocity accurately measures real world ambulation in Friedreich ataxia. Neurology. 2007;68(9):705-6.

42. Coleman CI, Sobieraj DM, Marinucci LN. Minimally important clinical difference of the Timed 25-Foot Walk Test: results from a randomized controlled trial in patients with multiple sclerosis. Curr Med Res Opin. 2012;28(1):49-56. doi:10.1185/03007995. 2011.639752.

43. Kaufman M, Moyer D, Norton J. The significant change for the Timed 25-foot Walk in the multiple sclerosis functional composite. Mult Scler. 2000;6(4):286-90.

44. Schwid SR, Goodman AD, McDermott MP, Bever CF, Cook SD. Quantitative functional measures in MS: what is a reliable change? Neurology. 2002;58(8):1294-6.

45. Beninato M, Gill-Body KM, Salles S, Stark PC, Black-Schaffer RM, Stein J. Determination of the minimal clinically important difference in the FIM instrument in patients with stroke. Arch Phys Med Rehabil. 2006;87(1):32-9. 